OPEN ACCESS

Edited by:

Andrea Zille,

University of Minho, Portugal

Reviewed by:

Zhen Lin,

Fujian Medical University, China Yizhong Lu,

University of Jinan, China

*Correspondence:

Yongri Jin

jinyr@jlu.edu.cn

Specialty section:

This article was submitted to Industrial Biotechnology,

a section of the journal

Frontiers in Bioengineering and

Biotechnology

Received: 07 October 2021 Accepted: 03 December 2021

Published: 03 January 2022

Citation:

Liu Y, Yan J, Huang Y, Sun Z, Zhang H, Fu L, LiX and Jin Y (2022) Single-Atom Fe-Anchored Nano-Diamond With Enhanced Dual-Enzyme Mimicking

Performance for $\mathrm{H}_{2} \mathrm{O}_{2}$ and

Glutathione Detection.

Front. Bioeng. Biotechnol. 9:790849.

doi: 10.3389/fbioe.2021.790849

\section{Single-Atom Fe-Anchored} Nano-Diamond With Enhanced Dual-Enzyme Mimicking Performance for $\mathrm{H}_{2} \mathrm{O}_{2}$ and Glutathione Detection

\author{
Ying Liu ${ }^{1}$, Jianghong Yan ${ }^{2}$, Yu Huang ${ }^{1}$, Zhiheng Sun ${ }^{1}$, Huijing Zhang ${ }^{1}$, Lihaoyuan Fu ${ }^{1}$, \\ Xuwen $\mathrm{Li}^{1}$ and Yongri $\mathrm{Jin}^{1 *}$
}

${ }^{1}$ College of Chemistry, Jilin University, Changchun, China, ${ }^{2}$ First Clinical Hospital, Jilin Province Academy of Traditional Chinese Medicine, Changchun, China

Glutathione $(\mathrm{GSH})$ is an important antioxidant and free radical scavenger that converts harmful toxins into harmless substances and excretes them out of the body. In the present study, we successfully prepared single-atom iron oxide-nanoparticle (Fe-NP)-modified nanodiamonds (NDs) named Fe-NDs via a one-pot in situ reduction method. This nanozyme functionally mimics two major enzymes, namely, peroxidase and oxidase. Accordingly, a colorimetric sensing platform was designed to detect hydrogen peroxide $\left(\mathrm{H}_{2} \mathrm{O}_{2}\right)$ and $\mathrm{GSH}$. Owing to their peroxidase-like activity, Fe-NDs can oxidize colorless $3,3^{\prime}, 5,5^{\prime}$-tetramethylbenzidine (TMB) into blue with sufficient linearity at $\mathrm{H}_{2} \mathrm{O}_{2}$ concentrations of 1-60 $\mu \mathrm{M}$ and with a detection limit of $0.3 \mu \mathrm{M}$. Furthermore, using different concentrations of GSH, oxidized TMB can be reduced to TMB, and the color change from blue to nearly colorless can be observed by the naked eye (linear range, 1-25 $\mu \mathrm{M}$; detection limit, $0.072 \mu \mathrm{M})$. The established colorimetric method based on oxidase-like activity can be successfully used to detect reduced GSH in tablets and injections with good selectivity and high sensitivity. The results of this study exhibited reliable consistency with the detection results obtained using high-performance liquid chromatography (HPLC). Therefore, the FeNDs colorimetric sensor designed in this study offers adequate accuracy and sensitivity.

Keywords: nanodiamond, single-atom Fe, peroxidase-like and oxidase-like activity, colorimetric sensor, glutathione

\section{INTRODUCTION}

Glutathione (GSH), an important tripeptide thiol ( $\gamma$-glutamyl cysteinyl glycine) antioxidant, is widely found in human cells and involved in several metabolic processes (Richie et al., 1996; Xu et al., 2016; Yan et al., 2016). It plays a significant role in biological systems, including the maintenance of protein structure, intracellular signal transduction, generegulation, and regulation of immune function. Changes in the concentration of GSH are directly associated with the occurrence of some diseases, such as neurodegenerative disorders, inflammation, heart disease, and cancer (Refsum et al., 1998; Zhang et al., 2004; Lu, 2009; Jung et al., 2013; Micke et al., 2015; González de Vega et al., 2016). Studies have shown that glutathione supplementation can prevent some diseases, such as cardiovascular disease, liver disease, diabetes, and delay aging (Micke et al., 2015; González de Vega et al., 2016). To date, various techniques have been proposed for GSH detection, such as fluorescence spectroscopy (Liu et al., 2016; Dong et al., 2017), high-performance liquid chromatography (HPLC) (Giustarini et al., 2004; Patterson et al., 2008), mass spectrometry (Huang and Chang, 2007; Zheng 
et al., 2007), absorbance spectroscopy (Li et al., 2010; Liu et al., 2013) and capillary electrophoresis (Musenga et al., 2007). All of these methods, absorbance spectroscopy has attracted more and more attention owing to its simplicity, lowcost, and convenience. In addition, nanomaterials as mimetic peroxidases have become a focus area for research, including $\mathrm{V}_{2} \mathrm{O}_{5}$ nanowires (André et al., 2011), 3D porous graphene nanocomposites (Wang et al., 2017) and $\mathrm{Fe}_{3} \mathrm{O}_{4}$ NPs (Liang and Yan, 2019) etc. The mimetic peroxidase can oxidize the substrate $3,3^{\prime}, 5,5^{\prime}$-tetramethyl benzidine (TMB) in the presence of hydrogen peroxide $\left(\mathrm{H}_{2} \mathrm{O}_{2}\right)$ with a colorimetric change from colorless to blue, which can be observed by the naked eye and analyzed using ultraviolet-visible spectrophotometry (UVvis) spectrophotometry. Nanomaterials are expected to perform multi-enzyme functions to achieve multiple uses of an enzyme, thus improving catalytic efficiency (Dong et al., 2014; Fan et al., 2018), or to achieve cascade catalysis, which often has greater advantages and application prospects. Currently, some nanomaterials have been reported to exhibit multi-enzymemimicking activity, such as $\mathrm{Co}_{3} \mathrm{O}_{4}$ nanoplates (Wang $\mathrm{H}$. et al., 2018), NiPd hNPs (Wang et al., 2016) and $\mathrm{Co}_{1.5} \mathrm{Mn}_{1.5} \mathrm{O}_{4}$ (Liu et al., 2021), etc. They can mimic either two, three, or all of the following four redox enzymes: peroxidase, oxidase, catalase, and superoxide dismutase. In addition to these enzymes, the less investigated simulated nanozymes include $\mathrm{V}_{2} \mathrm{O}_{5}$ with peroxidase-like and glucose oxidase (Gox)-like catalytic properties (Ding et al., 2020) and $\mathrm{Cu}_{2} \mathrm{O}$ NPs with cytochrome $c$ oxidase activity (Chen M. et al., 2017). Therefore, the development of new nanomaterials with multi-functional enzyme-mimicking properties is necessary.

As biocompatible carbon-based materials, nanodiamonds (NDs) have unique intrinsic properties such as superior hardness and chemical inertness (Grichko et al., 2008; Aleksenskiy et al., 2010; Shenderova et al., 2011). Owing to small size and facile surface functionalization, NDs exhibit lower cytotoxicity and superior biocompatibility than those exhibited by other carbon materials (Xing and Dai, 2009; Zhang et al., 2012; Qin et al., 2021). NDs and their derivatives have recently become interesting topics for cutting-edge research and revealed high application potential in biomedical fields, such as bioimaging, biosensing, implant coating, and drug delivery (Shimkunas et al., 2009; Narayan et al., 2011; Haziza et al., 2017; Su et al., 2019; Fang et al., 2020; Jariwala et al., 2020; Nowicki and Czarniewska, 2020). In addition to the bio-related applications, NDs with reactive oxygen-containing surfaces have exhibited a certain level of antibacterial effects (Wehling et al., 2014; Ong et al., 2018). Meanwhile, oxygenated NDs also emerged as multienzyme mimics under various reaction conditions (Chen T. M. et al., 2017; Fang et al., 2020). Furthermore, it was reported that oxygen-containing groups of NDs including carbonyl, carboxyl and hydroxyl groups are the active sites for the release of hydroxyl radical from $\mathrm{H}_{2} \mathrm{O}_{2}$ during oxidative dehydrogenation reaction (Sun et al., 2015; Wang Q. et al., 2018).

In the present study, we successfully prepared a single-atom Femodified NDs via a one-pot insitu reduction method. The effects of single-atom Fe on the visible optical absorption and charge carrier separation as well as Fe-NDs with peroxidase-like and oxidase-like activities have not yet been reported. In this study, the corresponding properties of Fe-NDs were investigated in detail. Moreover, in environments of harsh $\mathrm{pH}$ and high temperature, $\mathrm{Fe}$ NDs exhibit excellent catalytic capability and stability, enabling them very suitable for practical application. In the presence of $\mathrm{H}_{2} \mathrm{O}_{2}, \mathrm{Fe}-\mathrm{NDs}$ catalyzed the reaction of TMB to generate colored oxidation products, which were used for detecting $\mathrm{H}_{2} \mathrm{O}_{2}$. In the absence of $\mathrm{H}_{2} \mathrm{O}_{2}$, Fe-NDs oxidized colorless TMB to blue-colored oxidized TMB (oxTMB), which was reduced to colorless TMB by adding different concentrations of GSH (Scheme 1). The whole process can be observed with the naked eye and analyzed using $\mathrm{UV}$-vis spectroscopy. Importantly, the process exhibits a good linear relationship in the concentration range of $1-25 \mu \mathrm{M}$ with a

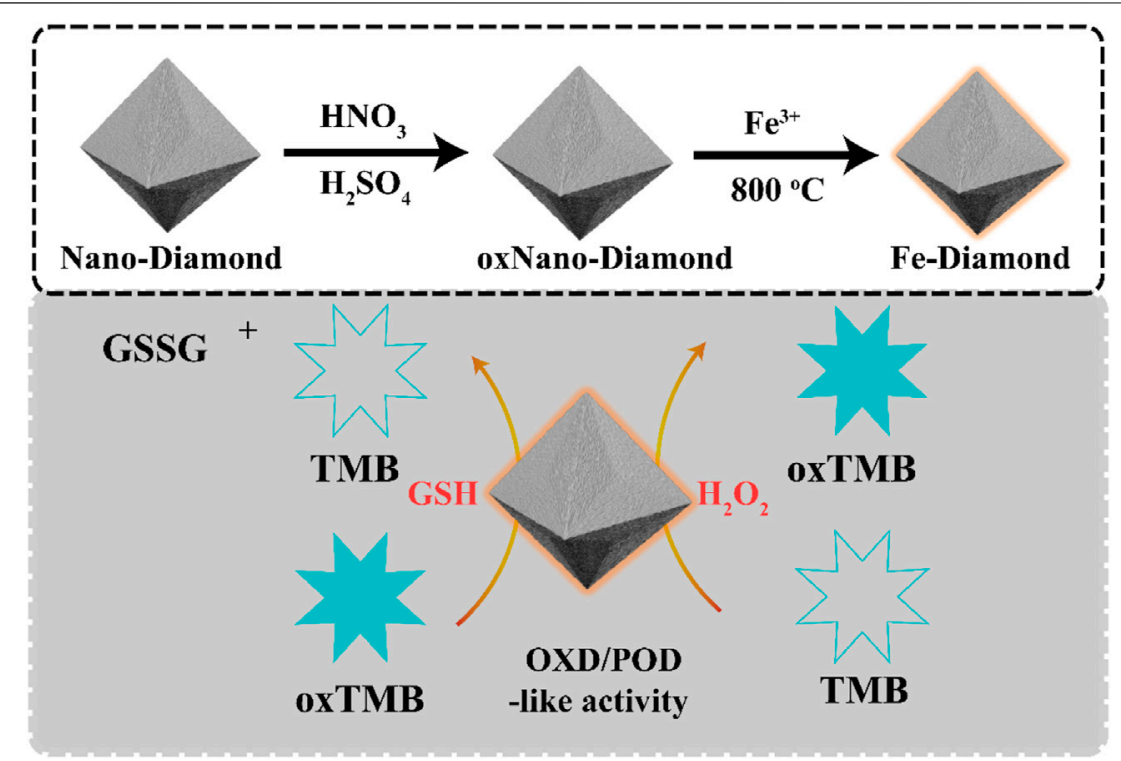

SCHEME 1 | Schematic presentation for Fe-NDs with peroxidase-like and oxidase-like activity. 
detection limit of $0.072 \mu \mathrm{M}$. Our sensor successfully determined reduced GSH in tablet and injection samples, and the results were also confirmed by using HPLC-UV.

\section{EXPERIMENTAL}

\section{Materials}

Nano-diamond, $\mathrm{FeCl}_{3}, \mathrm{H}_{2} \mathrm{SO}_{4}$ and $\mathrm{HNO}_{3}, \quad 3,3^{\prime}, 5,5^{\prime}$ tetramethylbenzidine (TMB), 1,2-diaminobenzene (OPD), 2,2' azinobis-(3-ethylbenzthiazoline-6-sulphonate) (ABTS), L- $\gamma$-glutamylL-cysteinylglycine (GSH), thiourea were purchased from Macklin reagent Co.,Ltd. (Shanghai, China), Human serum albumin (HAS), Bovine serum albumin (BSA), ascorbic acid (AA), glycine (Gly), Llysine (Lys), L-serine (Ser), D/L-cysteine(D-Cys, L-Cys), glucose, sodium chloride, calcium chloride, cupric sulfate, ferric chloride, potassium chloride, zinc sulfate, magnesium sulfate, tartaric acid, choline chloride were purchased from Sinopharm Chemical Reagent Co. Ltd. $\mathrm{NaN}_{3}$ was purchased fromTianjin Fuchen Chemical Reagent Factory. $\mathrm{H}_{2} \mathrm{O}_{2}$ was purchased from Xilong Scientific Co., Ltd. sodium chloride, calcium chloride, cupric sulfate, ferric chloride, potassium chloride, zinc sulfate, magnesium sulfate, tartaric acid, choline chloride was purchased fromSinopharm ChemicalReagent Co., Ltd. Sodium acetate buffer (0.1 M, pH = 4.0) were freshly prepared before use. All solutions prepared for purified water are derived from Wahaha purified water (China).

\section{Instrumentation}

X-ray powder diffraction (XRD) was collected on a PANalytical B.V. Empyrean powder diffractometer, in which data were collected from $5^{\circ}$ to $80^{\circ}$ at a scan rate of $10^{\circ} / \mathrm{min}$. Scanning electron microscopy (SEM) images were captured on a Hitachi FE-SEM S-4800 instrument with an acceleration voltage of $3 \mathrm{kV}$. Transmission electron microscopy (TEM) and high-resolution TEM (HRTEM) images was carried on a JEM-2100F. Spherical aberration corrected Transmission Electron Microscope (ACTEM) was carried on a JEM-ARM300F. UV-vis spectra were measured on UV-2700 Spectrophotometer (Shimadzu, Japan).

\section{Synthesis of Fe-NDs}

The purchased NDs $(0.2 \mathrm{~g})$ were dispersed in a mixture $(20 \mathrm{ml})$ of $\mathrm{H}_{2} \mathrm{SO}_{4}$ and $\mathrm{HNO}_{3}$ with a volume ratio of $3: 1$ and heated to $90^{\circ} \mathrm{C}$ for $2 \mathrm{~h}$. After the heating, the suspensions were cooled down to room temperature and neutralized by the adding of $\mathrm{NaOH}$ solution. After dialysis against water, the above suspensions were dispersed in $\mathrm{HCl}$ solution with a final concentration of $0.1 \mathrm{M}$ and heated at $90^{\circ} \mathrm{C}$ for another $2 \mathrm{~h}$. O-NDs with abundant specific oxygenated groups were obtained after proper dialysis and freeze-drying. Fe in the as-prepared O-NDs were added into $20 \mathrm{ml}$ distilled water. The obtained solution was heated at $90^{\circ} \mathrm{C}$ for $1 \mathrm{~h}$ under stirring, then the temperature was raised to $100^{\circ} \mathrm{C}$ for complete water evaporation. The resulting mixture was put into an alumina crucible with a cover, and heated to $700^{\circ} \mathrm{C}$ with the ramping rate of $20^{\circ} \mathrm{C} / \mathrm{min}$, and kept at that temperature for another $4 \mathrm{~h}$. This process was conducted with $30 \mathrm{ml} / \mathrm{min} \mathrm{N}_{2}$ flow at atmospheric pressure. Nano-diamond modified with single-atom $\mathrm{Fe}$ is denoted as Fe-NDs.

\section{Enzyme Mimicking Activities of Fe-NDs}

Fe-NDs with peroxidase-like activity can directly oxidize substrates in the presence of $\mathrm{H}_{2} \mathrm{O}_{2}$. The whole reaction system consists of $44 \mu \mathrm{l}$ of $0.18 \mathrm{mg} \mathrm{ml}^{-1}$ Fe-NDs, $50 \mu \mathrm{H} \mathrm{H}_{2} \mathrm{O}_{2}(1 \mathrm{mM})$ and $100 \mu \mathrm{l}$ of $4 \mathrm{mM}$, TMB were added to $806 \mu \mathrm{l}$ of $0.1 \mathrm{M}$ HAC-NaAC buffer solution $(\mathrm{pH}=4.0)$. Finally, the mixed system was reacted at $55^{\circ} \mathrm{C}$ for $15 \mathrm{~min}$ and the UV absorption was measured at $652 \mathrm{~nm}$.

The detective process of oxidase-like activity is similar to that of peroxidase mimics, except that no $\mathrm{H}_{2} \mathrm{O}_{2}$ is added. To assess the oxidase activity of Fe-NDs, Typically, $100 \mu \mathrm{l}$ of $0.18 \mathrm{mg} \mathrm{ml}^{-1} \mathrm{Fe}-\mathrm{NDs}$ and $100 \mu \mathrm{l}$ of $4 \mathrm{mM}$ TMB were added to $800 \mu \mathrm{l}$ of $0.1 \mathrm{M} \mathrm{HAC}-\mathrm{NaAC}$ buffer solution $(\mathrm{pH}=4.0)$. Finally, the mixed system was reacted at $40^{\circ} \mathrm{C}$ for $20 \mathrm{~min}$ and the UV absorption was measured at $652 \mathrm{~nm}$.

\section{Steady-State Kinetic Analysis}

The steady-state kinetics experiment of peroxide-like properties was carried out with Fe-NDs suspension $\left(44 \mu \mathrm{l}, 0.18 \mathrm{mg} \mathrm{ml}^{-1}\right)$, $\mathrm{H}_{2} \mathrm{O}_{2}(50 \mu \mathrm{l}, 1 \mathrm{mM})$, and TMB $(100 \mu \mathrm{l}, 4 \mathrm{mM})$. The mixed system was reacted at $55^{\circ} \mathrm{C}$ for $10 \mathrm{~min}$ before being used directly for UVvis absorbance measurements. Similarly, kinetic analysis of the oxidase-like properties was carried out with Fe-NDs suspension $\left(100 \mu \mathrm{l}, 0.18 \mathrm{mg} \mathrm{ml}^{-1}\right)$ by varying the concentration of TMB. The mixed system was reacted at $40^{\circ} \mathrm{C}$ for $10 \mathrm{~min}$ before being used directly for UV-vis absorbance measurements.

A typical experimental operation is to determine the reaction rate changes with different concentrations of TMB under optimal conditions. The kinetic parameters are determined by the following equations: $1 / v=K_{\mathrm{m}} / V_{\max } \cdot\left(1 /[\mathrm{S}]+1 / K_{\mathrm{m}}\right)$, where $v$ is the initial velocity, $V_{\max }$ is the maximal reaction velocity, and [S] is the concentration of the substrate. $K_{\mathrm{m}}$ is the Michaelis-Menten constant, which indicates the enzyme affinity for the substrate.

\section{Colorimetric Detection of Hydrogen Peroxide and Glutathione}

The working solution for $\mathrm{H}_{2} \mathrm{O}_{2}$ determination as follows: $44 \mu \mathrm{l}$ Fe-NDs suspension $\left(0.18 \mathrm{mg} \mathrm{ml}^{-1}\right), 100 \mu \mathrm{TMB}(4 \mathrm{mM})$ and different concentrations of $\mathrm{H}_{2} \mathrm{O}_{2}(1-60 \mu \mathrm{M}, 50 \mu \mathrm{l})$ were added into $806 \mu \mathrm{l}$ of $0.1 \mathrm{M} \mathrm{HAc-NaAc}$ buffer solution $(\mathrm{pH}=4.0)$. Then, the absorbance of the mixed solution at $652 \mathrm{~nm}$ was measured after incubation for $15 \mathrm{~min}$ at $55^{\circ} \mathrm{C}$ temperature.

The whole reaction system for GSH determination consisted of $100 \mu \mathrm{l} \mathrm{TMB}(4 \mathrm{mM}), 500 \mu \mathrm{l}$ of $0.1 \mathrm{M} \mathrm{HAc-NaAc}$ buffer solution $(\mathrm{pH}=4.0)$ and $100 \mu \mathrm{l}$ of Fe-NDs suspension $(0.18 \mathrm{mg}$ $\mathrm{ml}^{-1}$ ). After $20 \mathrm{~min}$ of reaction at $40^{\circ} \mathrm{C}$ temperature, the $300 \mu \mathrm{l}$ GSH solution was added, and then the absorbance is recorded on $\mathrm{UV}$-vis spectra at $625 \mathrm{~nm}$ after $15 \mathrm{~min}$. GSH concentration is calculated by measuring the change in absorbance $(\Delta \mathrm{A})$ of the reaction system after adding GSH. The blank group was given the same amount of ultrapure water instead of GSH.

\section{Detection of GSH in Drug Samples}

The glutathione tablets and injections were produced by Chongqing Yaoyou Pharmaceutical Co., LTD. The tablets and injections were prepared with a certain concentration of GSH test solution, followed by the addition of different concentrations of GSH standard solution to 5,10 , and $15 \mu \mathrm{M}$, so that the 


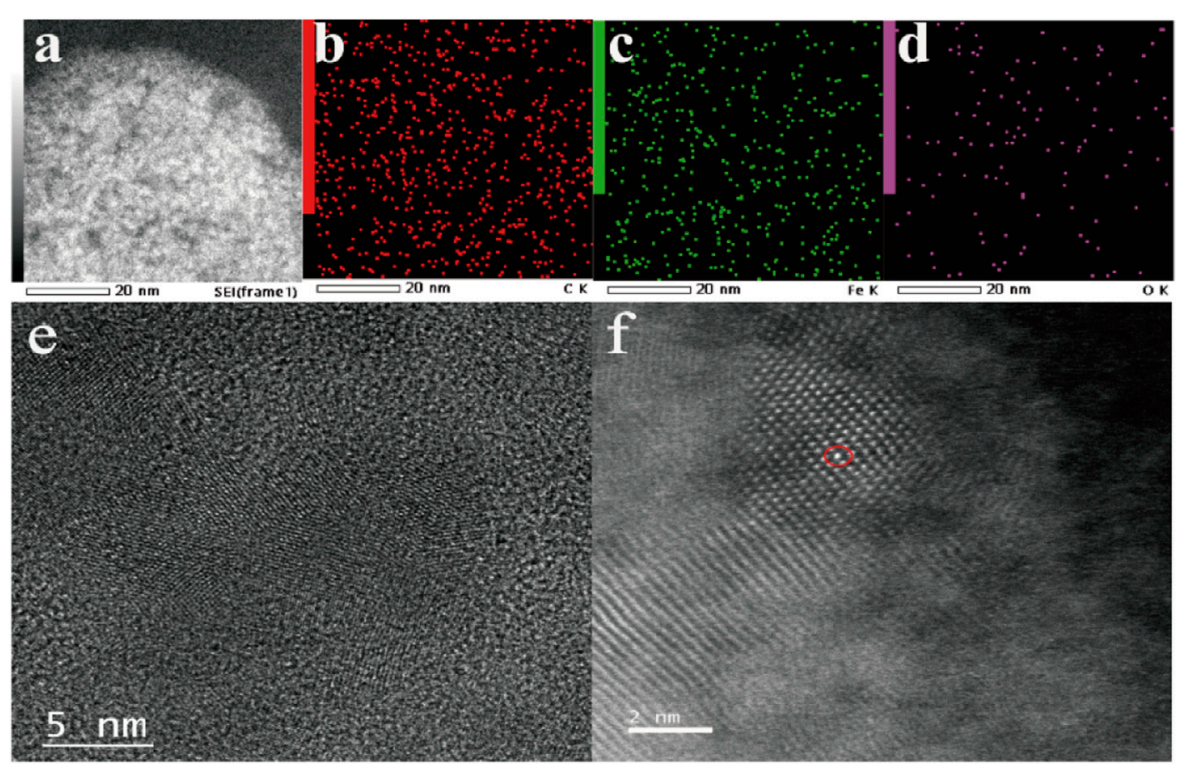

FIGURE 1 | (A) TEM images of Fe-ND; (B) Corresponding elemental mappings of component elements C, (C) Fe, (D) O; (E) HRTEM image of Fe-ND; (F) ACTEM of image of Fe-ND.

concentrations were detected in a linear range. The detection method of GSH was performed in accordance with 2.6.

\section{RESULTS AND DISCUSSION}

\section{Construction and Characterization of Fe-NDs}

Typically, Fe-NDs were well synthesized with the oxidized NDs asprecursors via coordination with iron, and the composite was further annealing at $800^{\circ} \mathrm{C}$. The presence of diamond in the sample is confirmed by the XRD pattern Supplementary Figure S1 (JCPDS No. 75-0219) (Chen T. M. et al., 2017). The size of the synthesized nanoparticles were irregular lamellar structure (Supplementary Figure S2). As demonstrated in Figures 1A-D, C, O, and Fe elements coexisted on the surface of NDs. These results suggest that Fe may exist as a single atom. In order to further verify the existence of $\mathrm{Fe}$ single atom, $\mathrm{Fe}$ atoms in $\mathrm{Fe}-\mathrm{NDs}$ samples were directly observed by using spherical aberration corrected Transmission Electron Microscope (ACTEM). As shown in Figures 1E,F, oxidized nano-diamond has lattice structure and abundant single Fe atoms are clearly observed as bright dots, indicating that Fe single atoms were successfully single dispersed on NDs.

\section{Peroxidase-Like Activity of Fe-NDs}

Several typical substrates \{i.e., TMB, OPD (1,2-diaminobenzene), and ABTS [2,2'-azinobis-(3-ethylbenzthiazoline-6-sulphonate)]\} were used to investigate the peroxidase activity of the synthesized FeNDs. Supplementary Figure S3 demonstrates that in the presence of $\mathrm{H}_{2} \mathrm{O}_{2}$, the three colorless substrates (TMB, OPD, and ABTS) were oxidized and turned blue, yellow, and green, respectively, indicating the presence of peroxidase activity in Fe-NDs. TMB was selected as the substrate to further confirm the results. Figure 2 demonstrates

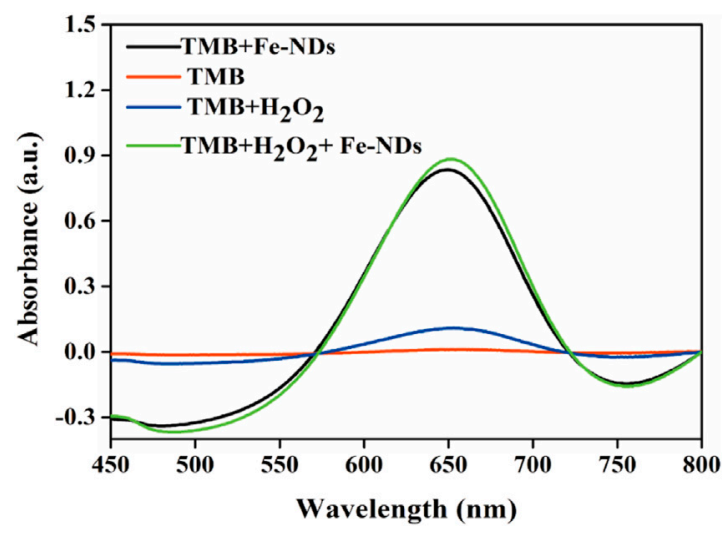

FIGURE 2 | Typical absorption spectra in different reaction systems of $\mathrm{TMB}, \mathrm{TMB}+\mathrm{H}_{2} \mathrm{O}_{2}, \mathrm{TMB}+\mathrm{Fe}-\mathrm{NDs}$, and $\mathrm{TMB}+\mathrm{H}_{2} \mathrm{O}_{2}+\mathrm{Fe}-\mathrm{NDs}$.

that in the absence of $\mathrm{H}_{2} \mathrm{O}_{2}$, TMB alone could not form chromogenic products. However, when Fe-NDs, TMB, and $\mathrm{H}_{2} \mathrm{O}_{2}$ were present in the reaction system, an increasing absorption was observedat $625 \mathrm{~nm}$, which indicated that Fe-NDs acted as peroxidase-like mimics in the catalytic reaction between TMB and $\mathrm{H}_{2} \mathrm{O}_{2}$.

Similar to the properties of horseradish peroxidase (HRP), the peroxidase-like properties of Fe-NDs depend on $\mathrm{pH}$, temperature, and $\mathrm{H}_{2} \mathrm{O}_{2}$ concentration. The activity of the material was measured at a $\mathrm{pH}$ of $2-9$ and a temperature of $25-70^{\circ} \mathrm{C}$ (Figures 3A-D). Figure $3 \mathrm{~A}$ demonstrates that the catalytic activity of Fe-NDs was greatly affected by $\mathrm{pH}$, and the highest activity was at a $\mathrm{pH}$ of 4 , which is similar to the activity of HRP and other reported peroxidelike enzymes (Zhang et al., 2013; Xia et al., 2015; Wang et al., 2017). In addition, Fe-NDs maintained a high catalytic activity in a wide 


\section{A}

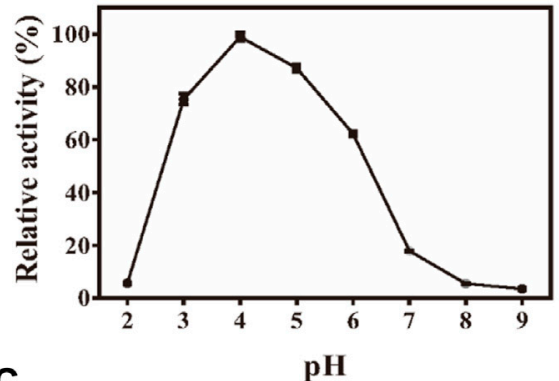

C

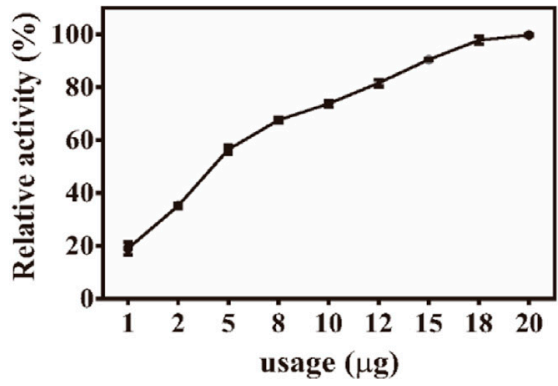

B
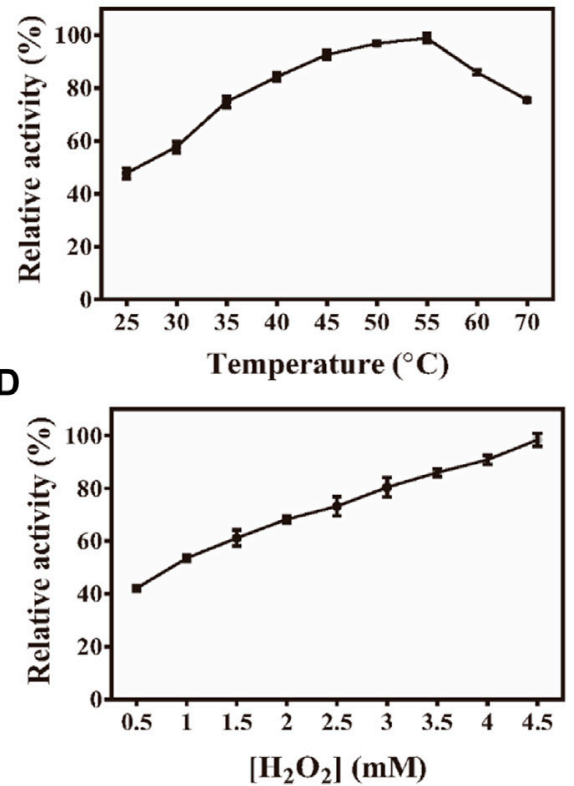

FIGURE 3 | (A) Effect of pH on the activity of Fe-NDs $+\mathrm{H}_{2} \mathrm{O}_{2}+\mathrm{TMB}$ system; (B) Effect of temperature on the activity of Fe-NDs $+\mathrm{H}_{2} \mathrm{O}_{2}+\mathrm{TMB}$ system; (C) Effect of catalyst dosage on the activity of Fe-NDs $+\mathrm{H}_{2} \mathrm{O}_{2}+\mathrm{TMB}$ system; (D) Effect of $\mathrm{H}_{2} \mathrm{O}_{2}$ concentrationon the activity of Fe-NDs $+\mathrm{H}_{2} \mathrm{O}_{2}+\mathrm{TMB}$ system. The error bars are the $\mathrm{SD}$ of the third parallel sample.

range of temperatures. As demonstrated in Figure 3B, Fe-NDs maintained more than $80 \%$ catalytic activity in the temperature range of $35-60^{\circ} \mathrm{C}$. The catalytic activity of Fe-NDs increased with an increase in the amount of material and concentration of $\mathrm{H}_{2} \mathrm{O}_{2}$ (Figure 3D). Eventually, the optimal experimental conditions were determined to be a $\mathrm{pH}$ of 4.0 , a temperature of $55^{\circ} \mathrm{C}$, and a material concentration of $8 \mu \mathrm{g} \mathrm{ml}^{-1}$.

\section{Oxidase-Like Activity of Fe-NDs}

Oxidases oxidize the peroxidase substrate TMB to produce bluecolored oxTMB. Oxidase activity was found in studying the peroxide-like activity of Fe-NDs, which was confirmed by TMB turned blue directly in the absence of $\mathrm{H}_{2} \mathrm{O}_{2}$ (Figure 2). To study the oxidase activity of NDs before and after the addition of $\mathrm{Fe}$, the change in absorbance at $652 \mathrm{~nm}$ was monitored using a UV-vis spectrometer. As demonstrated in Supplementary Figure S4, FeNDs significantly catalyzed TMB to produce a blue-colored reaction without $\mathrm{H}_{2} \mathrm{O}_{2}$. TMB is oxidized to oxTMB by oxygen in the presence of Fe-NDs, with a concomitant visible colorimetric change that can be observed by the naked eye. However, untreated NDs did not exhibit oxidase activity, indicating that the mixed acid oxidation process of NDs and the introduction of Fe played a key role in the oxidase activity of NDs. Fe-NDs can also oxidise different color-developing substrates (ABTS, which turns green, and OPD, which turns yellow) under certain conditions without adding $\mathrm{H}_{2} \mathrm{O}_{2}$, as demonstrated in Supplementary Figure S5. Therefore, the results indicated that Fe-NDs exhibited significant oxidase-like catalytic activity and directly catalysed the substrate.

Subsequently, the effects of different reaction conditions on the oxidase activity of Fe-NDs were studied. Parameters such as catalyst concentration, $\mathrm{pH}$, temperature, and TMB concentration were investigated (Figures 4A-D). To analyze the influence of $\mathrm{pH}$ on the catalytic activity of $\mathrm{Fe}-\mathrm{NDs}, \mathrm{pH}$ ranging from 2 to 7 was used in the colorimetric experiment. The results revealed that the optimal $\mathrm{pH}$ for the catalytic activity of Fe-NDs was 4.0. The temperature range of $25-60^{\circ} \mathrm{C}$ was used to analyze the influence of temperature on the catalytic activity of Fe-NDs. As demonstrated in Figure 4B, the catalytic activity of Fe-NDs remained above $80 \%$, proving that Fe-NDs exhibited catalytic activity over a wide temperature range. Eventually, $40^{\circ} \mathrm{C}$ was selected as the optimal temperature for follow-up experiments. In addition, we analyzed the influence of catalyst concentration ranging from 1 to $20 \mu \mathrm{g} \mathrm{ml}^{-1}$ on the activity of Fe-NDs. The results revealed that the catalytic activity of Fe-NDs increased rapidly when the concentration was $1-10 \mu \mathrm{g} \mathrm{ml}^{-1}$, and the growth rate was slow when the concentration was greater than $10 \mu \mathrm{g} \mathrm{ml}^{-1}$ until the activity reached the highest at $18 \mu \mathrm{g} \mathrm{ml}^{-1}$. Therefore, $18 \mu \mathrm{g} \mathrm{ml}^{-1}$ was determined as the optimal catalyst concentration. At the same time, the catalytic activity of Fe-NDs remained above $80 \%$ when the concentration of TMB was higher than $0.4 \mathrm{mM}$, so $0.4 \mathrm{mM}$ was selected as the optimal substrate concentration. The optimal experimental conditions were as follows: temperature, $40^{\circ} \mathrm{C} ; \mathrm{pH}, 4.0$; material concentration, $18 \mu \mathrm{g} \mathrm{ml} \mathrm{m}^{-1}$ and TMB concentration, $0.4 \mathrm{mM}$.

\section{Kinetic Analysis of Fe-NDs and Exploration of Reactive Oxygen Species}

To evaluate the peroxidase-like catalytic performance of Fe-NDs, the steady-state kinetic parameters were analyzed by changing the 

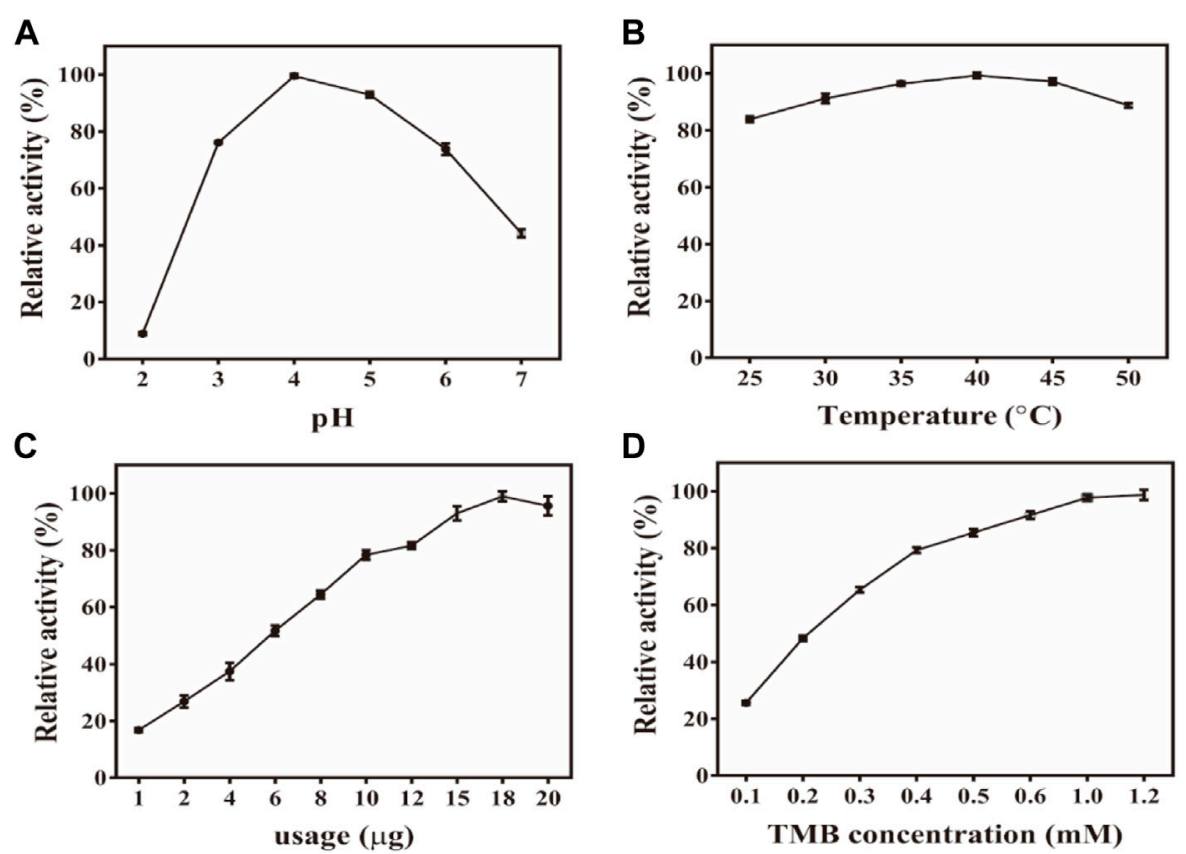

FIGURE 4 | (A) Effect of pH on the activity of Fe-NDs -TMB system; (B) Effect of temperature on the activity of Fe-NDs -TMB system; (C) Effect of catalyst dosage on the activity of Fe-NDs -TMB system; (D) Effect of TMB concentration on the activity of Fe-NDs -TMB system. The error bars are the SD of the third parallel sample.
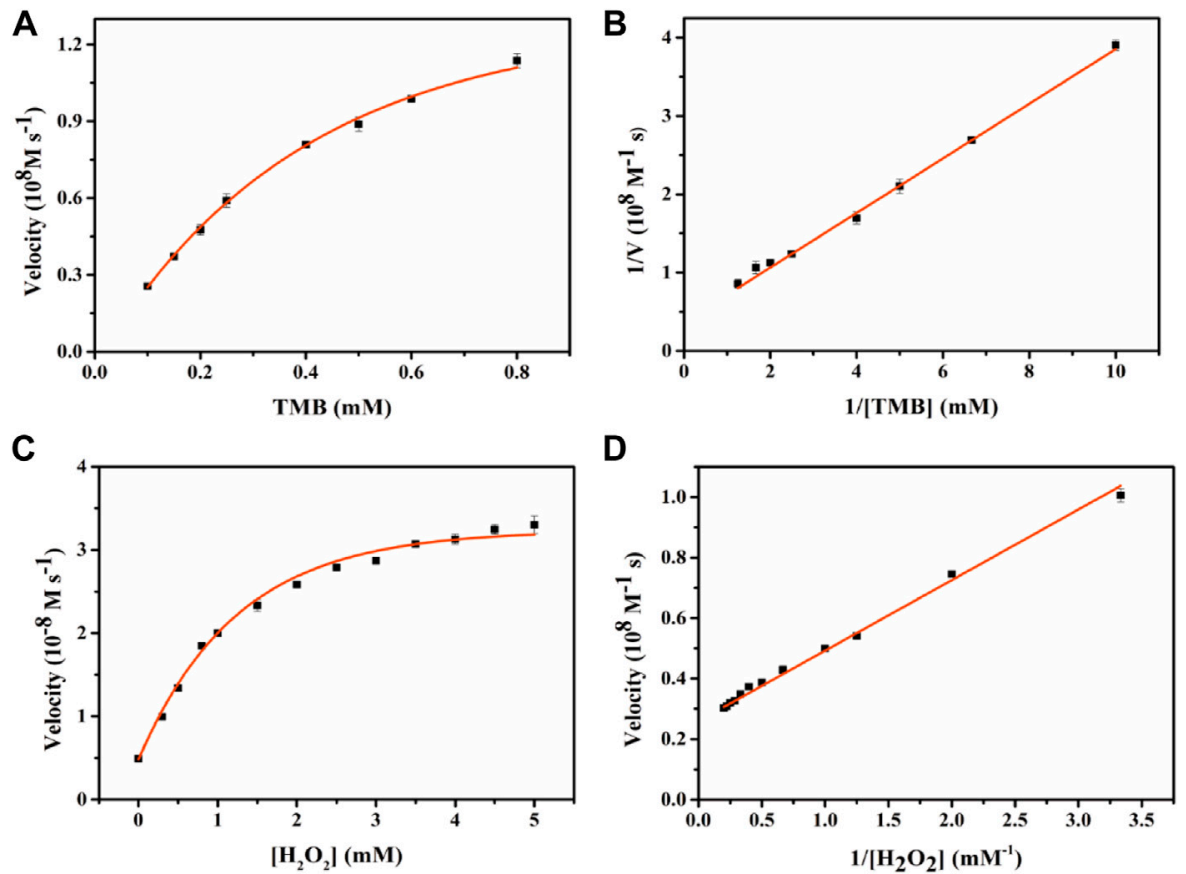

FIGURE 5 | Enzyme kinetics of Fe-NDs for POD-like activity. The concentration of $\mathrm{H}_{2} \mathrm{O}_{2}$ in (A) was $1 \mathrm{mM}$ and the TMB in (C) was $0.4 \mathrm{mM}$. (A) Kinetic plot of $v$ against TMB concentration; (B) Double reciprocal plot from (A); (C) Kinetic plot of $v$ against $\mathrm{H}_{2} \mathrm{O}_{2}$ concentration; (D) Double reciprocal plot from (C). The error bars are the standard deviation of the third parallel sample.

concentration of TMB and $\mathrm{H}_{2} \mathrm{O}_{2}$ in the reaction system. The absorbance of the TMB oxidation product, $\varepsilon=39000 \mathrm{M}^{-1} \mathrm{~cm}^{-1}$ $(652 \mathrm{~nm})$, was used to calculate the concentration of the substance corresponding to the absorbance. A typical Michaelis-Menten curve is shown in Figure 5, and the maximum initial velocity $\left(V_{\max }\right)$ and Michaelis-Menten constant $\left(K_{\mathrm{m}}\right)$ are provided in Supplementary 

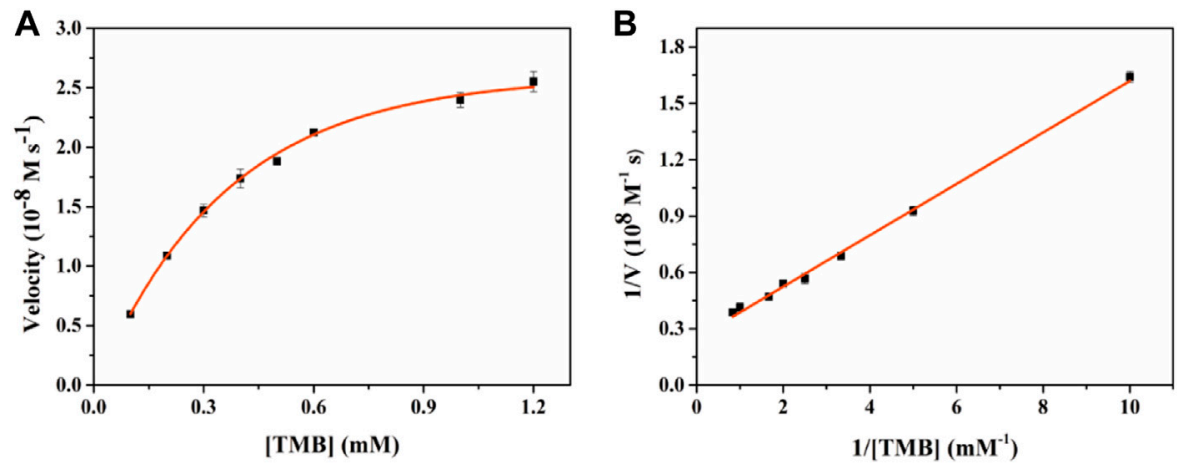

FIGURE 6 | Enzyme kinetics of Fe-NDs for OXD-like activity. The concentration of $\mathrm{H}_{2} \mathrm{O}_{2}$ in (A) was 1 mM. (A) Kinetic plot of $v$ against TMB concentration; (B) Double reciprocal plot from (A). The error bars are the standard deviation of the third parallel sample.
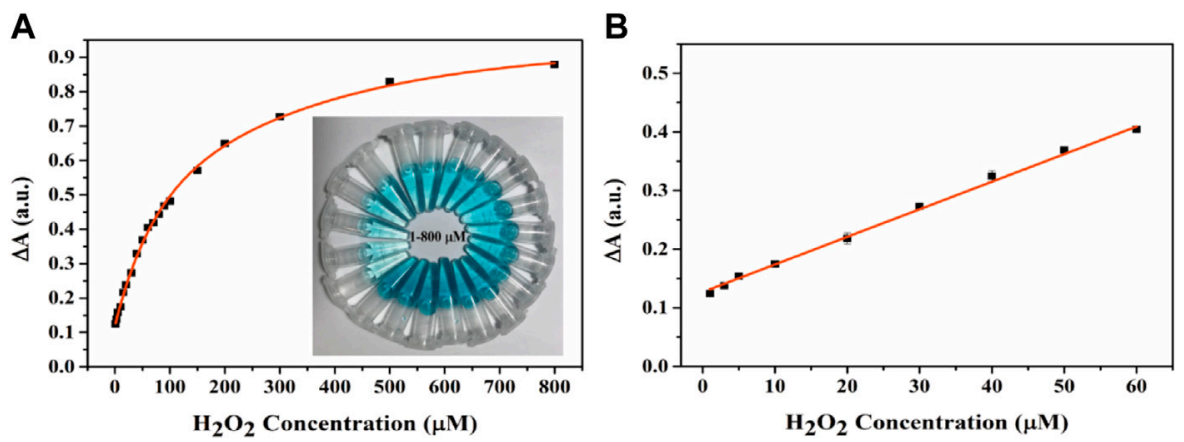

FIGURE 7 | (A) The UV-vis spectra and corresponding color changes (inset image) of the Fe-NDs + TMB system in the presence of a various concentrations of $\mathrm{H}_{2} \mathrm{O}_{2}$. (B) Good linear calibration plots for $\mathrm{H}_{2} \mathrm{O}_{2}$ detection. The error bars are the SD of the third parallel sample.
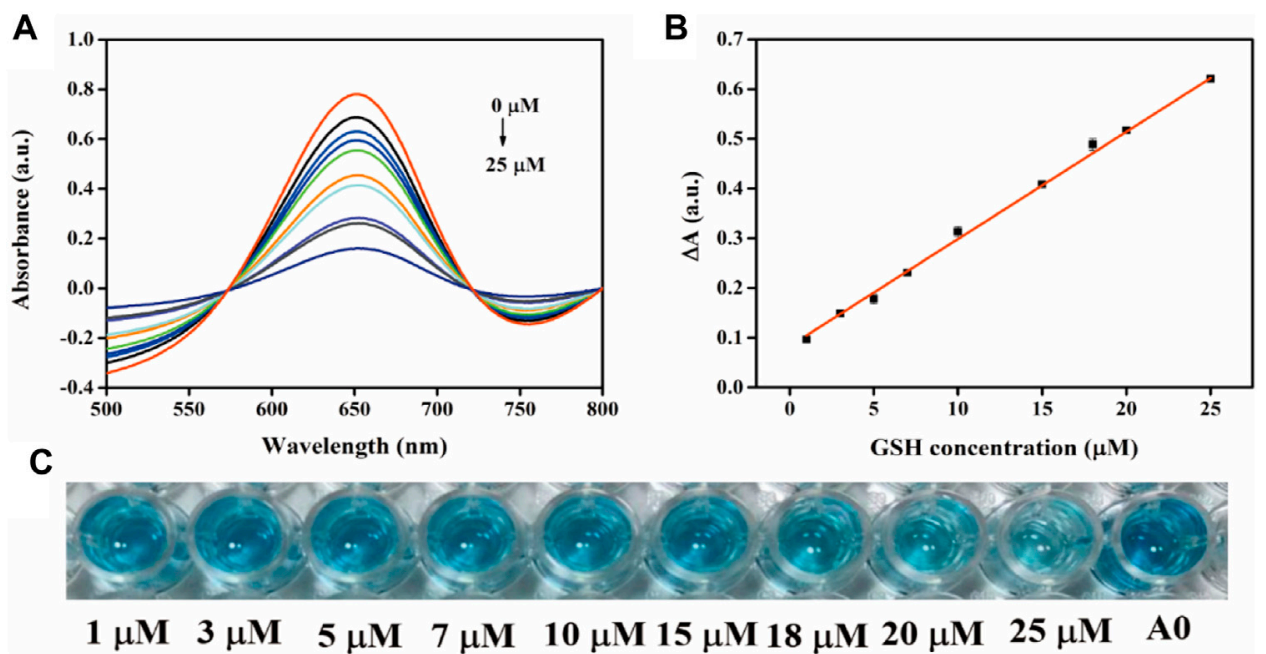

FIGURE 8 | (A) UV-vis spectra of the sensing system with different GSH concentrations; (B) Linear plots of $\Delta$ A versus GSH concentration; (C) an overview photograph. 
Table S1. It was observed that Fe-NDs exhibited a stronger affinity in terms of $\mathrm{H}_{2} \mathrm{O}_{2}\left(K_{\mathrm{m}}=0.87 \mathrm{mM}\right)$ compared to horseradish peroxidase (HRP) $\left(K_{\mathrm{m}}=3.7 \mathrm{mM}\right)$. Furthermore, the $K_{\mathrm{m}}$ value of Fe-NDs was $0.76 \mathrm{mM}$ when TMB was used as the substrate, suggesting that a higher concentration of TMB is required to achieve maximal enzymatic activity for the prepared nanozyme.

To better understand the catalytic mechanism of POD-like nanozyme, we used some free radical trapping agents. Results as shown in Supplementary Figure S6, p-benzoquinone, $\mathrm{NaN}_{3}$, and thiourea were captured by the superoxide radicals $\left(\mathrm{O}_{2}{ }^{-}\right)$, singlet oxygen molecules $\left({ }^{1} \mathrm{O}_{2}\right)$, and hydroxyl free radicals $(\mathrm{OH} \cdot)$, respectively. In the presence of thiourea in the system, the catalytic activity of Fe-NDs is significantly lower than that of the blank. The addition of p-benzoquinone can reduce the catalytic activity by about $10 \%$. The main active substance produced in the TMB oxidation process is $\mathrm{OH}$. and a little $\mathrm{O}_{2}{ }^{-}$. is also produced in this process.

To further evaluate the oxidase-like catalytic performance of Fe-NDs, the kinetic experiment was performed by changing the concentration of TMB under optimal experimental conditions. A typical Michaelis-Menten curve is demonstrated in Figure 6, and the maximum initial velocity $V_{\max }$ and $K_{\mathrm{m}}$ calculated are provided in Supplementary Table S2. The values of $K_{\mathrm{m}}$ and $V_{\text {max }}$ were $0.55 \mathrm{mM}$ and $4.01 \times 10^{-8} \mathrm{M} \mathrm{s}^{-1}$, respectively, when TMB was used as the substrate. Compared with the classic $\mathrm{CeO}_{2}$ NPs, Fe-NDs had a higher affinity for TMB, which may be attributed to the uniform dispersion of $\mathrm{Fe}$ atoms on the diamond surface enhancing its catalytic properties.

Oxygen plays an important role as an electron acceptor in the catalytic activity of oxidases. The reaction solution was pre-treated with nitrogen and oxygen for half an hour to confirm the role of oxygen in catalysis, and Fe-NDs were subsequently added to catalyze TMB under optimal conditions. As demonstrated in Supplementary Figure S7, under the saturation condition of nitrogen, the catalytic activity of Fe-NDs was significantly inhibited and was only $40 \%$. However, under the saturation condition of oxygen, the catalytic activity was significantly increased to $72 \%$ compared with that in the air, which proved that oxygen played an important role in the oxidation of TMB. The oxidase activity of Fe-NDs may be attributed to the reactive oxygen species (ROS) produced during the oxidation of TMB. To analyze the influence of different free radicals on the reaction system, we used different concentrations of p-benzoquinone, $\mathrm{NaN}_{3}$, and thiourea to scavenge thesuperoxide radicals $\left(\mathrm{O}_{2}{ }^{-}\right)$, singlet oxygen molecules $\left({ }^{1} \mathrm{O}_{2}\right)$, and hydroxyl free radicals $(\mathrm{OH} \cdot)$, respectively. The results are demonstrated in Supplementary Figure S8, the three different concentrations of trapping agents can inhibit the catalytic activity of Fe-NDs, indicating that the system produces three kinds of ROS, which are $\mathrm{O}_{2} \cdot{ }^{-},{ }^{1} \mathrm{O}_{2}$, and $\mathrm{OH}$. respectively.

\section{Colourimetric Assessment of $\mathrm{H}_{2} \mathrm{O}_{2}$}

$\mathrm{H}_{2} \mathrm{O}_{2}$ has been associated with cell damage and several diseases (Song et al., 2010; Fu et al., 2014). Therefore, it is important to establish a simple, highly sensitive, rapid technique for the visual detection of $\mathrm{H}_{2} \mathrm{O}_{2}$. The experimental results of $\mathrm{H}_{2} \mathrm{O}_{2}$ detection by Fe-NDs colorimetric method are demonstrated in Figures $\mathbf{7 A , B}$, it demonstrated that the absorbance of TMB

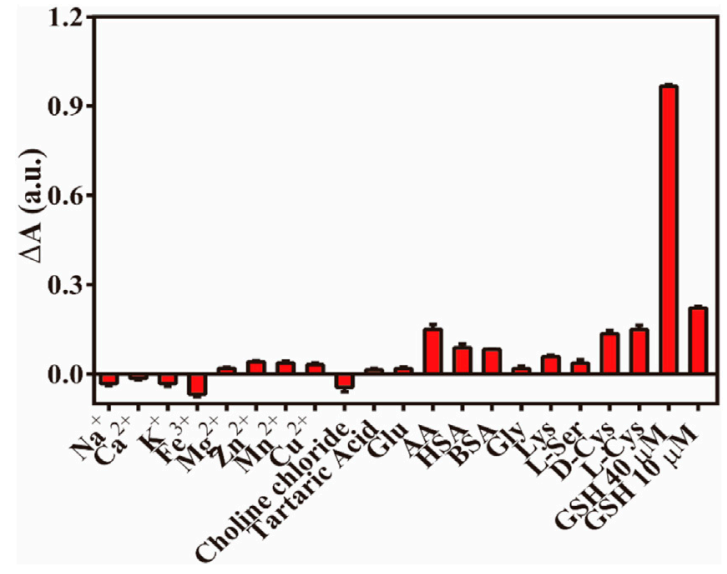

FIGURE 9 | The $\triangle \mathrm{A}$ responses of Fe-NDs + TMB system towards GSH and interferents (HAS and BSA, $1 \mathrm{mg} \mathrm{ml}^{-1}$; others, $1 \mathrm{mM}$ ). Error bar represents the standard deviation for three determinations.

increases with an increase in $\mathrm{H}_{2} \mathrm{O}_{2}$ concentration and exhibits a good linear relationship with $\mathrm{H}_{2} \mathrm{O}_{2}$ concentration $(1-60 \mu \mathrm{M}$; $\left.\mathrm{R}^{2}=0.9989\right)$. According to the $3 \sigma$ rule the detection limit for $\mathrm{H}_{2} \mathrm{O}_{2}$ was calculated to be $0.3 \mu \mathrm{M}$, indicating that the $\mathrm{H}_{2} \mathrm{O}_{2}$ sensor had a low detection limit. As demonstrated in Figure $7 \mathbf{A}$, the color of the solution deepened with increasing $\mathrm{H}_{2} \mathrm{O}_{2}$ concentration, indicating that the sensor exhibited excellent visual detection performance. Compared with other sensors based on peroxide-like activity used for detecting $\mathrm{H}_{2} \mathrm{O}_{2}$, as mentioned in Supplementary Table S3, the colorimetric method used in this study has a higher sensitivity and lower detection limit.

\section{Colourimetric Assessment of GSH}

GSH is a typical reducing agent that can directly reduce bluecolored oxTMB to colorless TMB owing to its rich mercapto functional groups (Liu et al., 2013). Differences in absorbance $(\triangle \mathrm{A})$ before and after adding GSH exhibited a good linear relationship with the concentration of GSH in the solution within a certain range. Based on changes in the absorbance value before and after $(\Delta \mathrm{A})$ detection, the Fe-NDs colorimetric biosensor was established to quantitatively detect GSH. To determine the optimal conditions for GSH detection, we studied the effects of $\mathrm{pH}$, temperature, and material concentration on the catalytic activity of Fe-NDs in the presence of GSH $(20 \mu \mathrm{M})$ (Supplementary Figure S9). As demonstrated in Supplementary Figure S9A, pH had an impact on the reaction system. The highest relative activity was achieved by deducting blank when $\mathrm{pH}$ was 4.0 . Therefore, a $\mathrm{pH}$ of 4.0 was considered optimal for subsequent experiments. No significant difference was observed in the value of $\Delta \mathrm{A}$ in the temperature range of $25-50^{\circ} \mathrm{C}$ (Supplementary Figure S9B). Considering the optimal detection conditions, $40^{\circ} \mathrm{C}$ was selected as the optimal temperature. Based on the combined results of detection using different $\mathrm{pH}$, temperature, catalyst dosage, and TMB concentration (Supplementary Figure S9D), the optimal 
TABLE 1 | Results of GSH analysis for tablets and injection solutions.

\begin{tabular}{|c|c|c|c|c|c|}
\hline Sample & $\begin{array}{c}\text { Found in } \\
\text { sample }(\mu \mathrm{M})\end{array}$ & Spiked $(\mu \mathrm{M})$ & Found $(\mu \mathrm{M})$ & Recovery (\%) & RSD (\%) \\
\hline Tablets & 5.09 & - & - & - & - \\
\hline- & - & 10.00 & 15.07 & 99.8 & 1.7 \\
\hline- & - & 15.00 & 19.27 & 94.6 & 1.5 \\
\hline Injection & 4.96 & - & - & - & - \\
\hline- & - & 15.00 & 19.54 & 97.2 & 1.8 \\
\hline
\end{tabular}

conditions for GSH detection were as follows: $\mathrm{pH}, 4.0$; temperature, $40^{\circ} \mathrm{C}$; Fe-ND concentration, $18 \mu \mathrm{g} \mathrm{ml}{ }^{-1}$ and TMB concentration, $0.4 \mathrm{mM}$.

A simple, fast, and sensitive visual colorimetric sensor for GSH detection can be established based on the properties of oxidases. Figure 8A demonstrates the UV-vis spectrum curve for detecting the absorption value of GSH in the concentration range of $1-25 \mu \mathrm{M}$ at $652 \mathrm{~nm}$. The corresponding calibration curve in the range of $1-25 \mu \mathrm{M}\left(\mathrm{R}^{2}=0.9997\right)$ is demonstrated in Figure 8B. A good linear relationship was observed between $\triangle \mathrm{A}$ and $\mathrm{GSH}$ concentration, and the equation was as follows: $\Delta \mathrm{A}=0.01$ [GSH] $(\mu \mathrm{M})+0.027$. The detection limit for GSH was $0.072 \mu \mathrm{M}$ according to the three-sigma $(3 \sigma)$ rule, which indicates that the colorimetric sensor can be used for reliable detection of GSH in real samples. As demonstrated in Figure $\mathbf{8 C}$, the color of the solution gradually became lighter as the concentration of GSH increased, indicating that the modified sensor had adequate visual detection performance. The Fe-NDbased sensor had a lower detection limit than the previously published nanoenzyme-based colorimetric GSH sensors mentioned in Supplementary Table S4, indicating the high sensitivity of the method.

\section{Selectivity and Stability of Fe-NDs}

To evaluate the anti-interference performance of the established colorimetric sensor, various co-existing disturbance species were tested under the same conditions, including various metal ions $\left(\mathrm{Na}^{+}, \mathrm{K}^{+}, \mathrm{Ca}^{2+}, \mathrm{Fe}^{3+}, \mathrm{Mg}^{2+}, \mathrm{Cu}^{2+}, \mathrm{Zn}^{2+}\right.$, and $\left.\mathrm{Mn}^{2+}\right)$, amino acids [glycine, lysine, L-serine and D/L(+)-cysteine], HAS, BSA, glucose, tartaric acid, choline chloride, and ascorbic acid. As demonstrated in Figure 9, the concentration of these cationic interfering species and amino acids was 100 times $(1 \mathrm{mM})$ that of GSH, and their influence on the absorbance value of the Fe-NDs/TMB system was negligible. Some biological macromolecules such as BSA (1 mg/ $\mathrm{mL})$ and HSA $(1 \mathrm{mg} / \mathrm{mL})$ had also little influence on the system. The absorbance values $(\Delta \mathrm{A})$ of $\mathrm{AA}$ and $\mathrm{D} / \mathrm{L}(+)$-cysteine were similar to those of the $10 \mu \mathrm{M}$ GSH solution; however, the difference in concentration of AA $(1 \mathrm{mM})$ and $\mathrm{D} / \mathrm{L}(+)$-cysteine $(1 \mathrm{mM})$ and GSH $(10 \mu \mathrm{M})$ solution was 100 times, and its effect could be ignored. Therefore, the proposed method has a higher selectivity for GSH detection and can be widely used for the rapid quantification of biological and biomedicine samples.

As demonstrated in Supplementary Figure S10, the stability of the oxidase-like activity of Fe-NDs was investigated. The catalytic activity of Fe-NDs remained above $80 \%$ at room temperature for 60 days, indicating that the material has good stability.

\section{Application of the GSH Sensor}

We used some drug samples to demonstrate the feasibility of this method to detect GSH in a complex environment and the results are provided in Supplementary Table S5. Statistical analysis indicate that the recovery rates of GSH in tablets and injections were in the range of $94.6-101.5 \%$ (RSD, 1.5-1.9\%) and $97.2-98.5 \%$ (RSD, 1.2-2.0\%), respectively (Table 1). All these results demonstrate that the proposed method is reliable for practical applications. At the same time, HPLC-UV was used to verify the accuracy of the Fe-NDs colorimetric sensor (National Pharmacopoeia Committee, 2020). The final results showed that the Fe-NDs colorimetric sensor designed in this paper has good accuracy and sensitivity which can be used to detect GSH in actual samples.

\section{CONCLUSION}

In conclusion, this study is the first of its kind to demonstrate the preparation of two-dimensional lamellar nanostructures containing iron using a hydrothermal method. The method is simple and environment-friendly. The prepared Fe-NDs could mimic two types of enzymes with peroxidase-like and oxidaselike activities. Studies have demonstrated that Fe-NDs exhibit excellent catalytic activity and long-term stability in harsh environments. Improvement in the catalytic activity of $\mathrm{Fe}-\mathrm{NDs}$ is mainly attributed to the introduction of Fe. Based on the enhanced catalytic activity, we successfully constructed a novel $\mathrm{H}_{2} \mathrm{O}_{2}$ sensor and $\mathrm{GSH}$ detector. The proposed Fe-NDs nanozyme-based visual sensing platform exhibits satisfying sensitivity, selectivity, and stability. This study provides a novel method for the preparation of various nanozyme materials and promotes the development and application of nanozymes in chemical and medical diagnosis.

\section{DATA AVAILABILITY STATEMENT}

The original contributions presented in the study are included in the article/Supplementary Material, further inquiries can be directed to the corresponding author. 


\section{AUTHOR CONTRIBUTIONS}

YJ designed experiments; YL, JY, and YH carried out experiments; $\mathrm{ZS}$ and $\mathrm{HZ}$ analyzed experimental results. YL and $\mathrm{XL}$ wrote the manuscript.

\section{REFERENCES}

Aleksenskiy, A., Baidakova, M., Osipov, V., and Vul', A. (2010). The Fundamental Properties and Characteristics of Nanodiamonds. Nanodiamonds 55, 77. doi:10.1007/978-1-4419-0531-4_3

André, R., Natálio, F., Humanes, M., Leppin, J., Heinze, K., Wever, R., et al. (2011). V2O5 Nanowires with an Intrinsic Peroxidase-like Activity. Adv. Funct. Mater. 21, 501-509. doi:10.1002/adfm.201001302

Chen, M., Wang, Z., Shu, J., Jiang, X., Wang, W., Shi, Z.-H., et al. (2017a). Mimicking a Natural Enzyme System: Cytochrome C Oxidase-like Activity of $\mathrm{Cu} 2 \mathrm{O}$ Nanoparticles by Receiving Electrons from Cytochrome C. Inorg. Chem. 56, 9400-9403. doi:10.1021/acs.inorgchem.7b01393

Chen, T. M., Tian, X. M., Huang, L., Xiao, J., and Yang, G. W. (2017b). Nanodiamonds as $\mathrm{pH}$-Switchable Oxidation and Reduction Catalysts with Enzyme-like Activities for Immunoassay and Antioxidant Applications. Nanoscale 9, 15673-15684. doi:10.1039/c7nr05629j

Ding, Y., Ren, G., Wang, G., Lu, M., Liu, J., Li, K., et al. (2020). V2O5 Nanobelts Mimick Tandem Enzymes to Achieve Nonenzymatic Online Monitoring of Glucose in Living Rat Brain. Anal. Chem. 92, 4583-4591. doi:10.1021/ acs.analchem.9b05872

Dong, J., Song, L., Yin, J.-J., He, W., Wu, Y., Gu, N., et al. (2014). Co3O4 Nanoparticles with Multi-Enzyme Activities and Their Application in Immunohistochemical Assay. ACS Appl. Mater. Inter. 6, 1959-1970. doi:10.1021/am405009f

Dong, Z.-Z., Lu, L., Ko, C.-N., Yang, C., Li, S., Lee, M.-Y., et al. (2017). A $\mathrm{MnO} 2$ nanosheet-Assisted GSH Detection Platform Using an Iridium(iii) Complex as a Switch-On Luminescent Probe. Nanoscale 9, 4677-4682. doi:10.1039/C6NR08357A

Fan, K., Xi, J., Fan, L., Wang, P., Zhu, C., Tang, Y., et al. (2018). In Vivo guiding Nitrogen-Doped Carbon Nanozyme for Tumor Catalytic Therapy. Nat. Commun. 9, 1440-1451. doi:10.1038/s41467-018-03903-8

Fang, J., Wang, H., Bao, X., Ni, Y., Teng, Y., Liu, J., et al. (2020). Nanodiamond as Efficient Peroxidase Mimic against Periodontal Bacterial Infection. Carbon 169, 370-381. doi:10.1016/j.carbon.2020.07.055

Fu, P. P., Xia, Q., Hwang, H.-M., Ray, P. C., and Yu, H. (2014). Mechanisms of Nanotoxicity: Generation of Reactive Oxygen Species. J. Food Drug Anal. 22, 64-75. doi:10.1016/j.jfda.2014.01.005

Giustarini, D., Dalle-Donne, I., Colombo, R., Milzani, A., and Rossi, R. (2003). An Improved HPLC Measurement for GSH and GSSG in Human Blood. Free Radic. Biol. Med. 35, 1365-1372. doi:10.1016/j.freeradbiomed.2003.08.013

González de Vega, R., Fernández-Sánchez, M. L., Fernández, J. C., Álvarez Menéndez, F. V., and Sanz-Medel, A. (2016). Selenium Levels and Glutathione Peroxidase Activity in the Plasma of Patients with Type II Diabetes Mellitus. J. Trace Elem. Med. Biol. 37, 44-49. doi:10.1016/ j.jtemb.2016.06.007

Grichko, V., Tyler, T., Grishko, V. I., and Shenderova, O. (2008). Nanodiamond Particles Forming Photonic Structures. Nanotechnology 19, 225201-225207. doi:10.1088/0957-4484/19/22/225201

Haziza, S., Mohan, N., Loe-Mie, Y., Lepagnol-Bestel, A.-M., Massou, S., Adam, M.P., et al. (2017). Fluorescent Nanodiamond Tracking Reveals Intraneuronal Transport Abnormalities Induced by Brain-Disease-Related Genetic Risk Factors. Nat. Nanotech 12, 322-328. doi:10.1038/nnano.2016.260

Huang, Y.-F., and Chang, H.-T. (2007). Analysis of Adenosine Triphosphate and Glutathione through Gold Nanoparticles Assisted Laser Desorption/ionization Mass Spectrometry. Anal. Chem. 79, 4852-4859. doi:10.1021/ac070023x

Jariwala, D. H., Patel, D., and Wairkar, S. (2020). Surface Functionalization of Nanodiamonds for Biomedical Applications. Mater. Sci. Eng. C 113, 110996. doi:10.1016/j.msec.2020.110996

\section{SUPPLEMENTARY MATERIAL}

The Supplementary Material for this article can be found online at: https://www.frontiersin.org/articles/10.3389/fbioe.2021.790849/ full\#supplementary-material

Jung, H. S., Chen, X., Kim, J. S., and Yoon, J. (2013). Recent Progress in Luminescent and Colorimetric Chemosensors for Detection of Thiols. Chem. Soc. Rev. 42, 6019-6031. doi:10.1039/C3CS60024F

Li, Y., Wu, P., Xu, H., Zhang, H., and Zhong, X. (2010). Anti-aggregation of Gold Nanoparticle-Based Colorimetric Sensor for Glutathione with Excellent Selectivity and Sensitivity. Analyst 136, 196-200. doi:10.1039/c0an00452a

Liang, M., and Yan, X. (2019). Nanozymes: From New Concepts, Mechanisms, and Standards to Applications. Acc. Chem. Res. 52, 2190-2200. doi:10.1021/ acs.accounts.9b00140

Liu, T., Huo, F., Li, J., Chao, J., Zhang, Y., and Yin, C. (2016). A Fast Response and High Sensitivity Thiol Fluorescent Probe in Living Cells. Sensors Actuators B: Chem. 232, 619-624. doi:10.1016/j.snb.2016.04.014

Liu, X., Wang, Q., Zhang, Y., Zhang, L., Su, Y., and Lv, Y. (2013). Colorimetric Detection of Glutathione in Human Blood Serum Based on the Reduction of Oxidized TMB. New J. Chem. 37, 2174-2178. doi:10.1039/c3nj40897c

Liu, X., Yang, J., Cheng, J., Xu, Y., Chen, W., and Li, Y. (2021). Facile Preparation of Four-In-One Nanozyme Catalytic Platform and the Application in Selective Detection of Catechol and Hydroquinone. Sensors Actuators B: Chem. 337, 129763. doi:10.1016/j.snb.2021.129763

Lu, S. C. (2009). Regulation of Glutathione Synthesis. Mol. Aspects Med. 30, 42-59. doi:10.1016/j.mam.2008.05.005

Micke, P., Beeh, K. M., Schlaak, J. F., and Buhl, R. (2001). Oral Supplementation with Whey Proteins Increases Plasma Glutathione Levels of HIV-Infected Patients. Eur. J. Clin. Invest. 31, 171-178. doi:10.1046/j.1365-2362.2001.00781.x

Musenga, A., Mandrioli, R., Bonifazi, P., Kenndler, E., Pompei, A., and Raggi, M. A. (2007). Sensitive and Selective Determination of Glutathione in Probiotic Bacteria by Capillary Electrophoresis-Laser Induced Fluorescence. Anal. Bioanal. Chem. 387, 917-924. doi:10.1007/s00216-006-0980-6

Narayan, R. J., Boehm, R. D., and Sumant, A. V. (2011). Medical Applications of diamond Particles \& Surfaces. Mater. Today 14, 154-163. doi:10.1016/s13697021(11)70087-6

National Pharmacopoeia Committee (2020). Pharmacopoeia of People' S Republic of China, Part 2. Beijing: China Medical Science and Technology Press, 629.

Nowicki, P., and Czarniewska, E. (2020). Nanodiamenty: Unikalne Nanocząsteczki Do Zastosowania W Biomedycynie I Biotechnologii. Postepy Biochem. 65, 247-262. doi:10.18388/pb.2019_281

Ong, S. Y., van Harmelen, R. J. J., Norouzi, N., Offens, F., Venema, I. M., Habibi Najafi, M. B., et al. (2018). Interaction of Nanodiamonds with Bacteria. Nanoscale 10, 17117-17124. doi:10.1039/C8NR05183F

Patterson, A. D., Li, H., Eichler, G. S., Krausz, K. W., Weinstein, J. N., Fornace, A. J., et al. (2008). UPLC-ESI-TOFMS-Based Metabolomics and Gene Expression Dynamics Inspector Self-Organizing Metabolomic Maps as Tools for Understanding the Cellular Response to Ionizing Radiation. Anal. Chem. 80, 665-674. doi:10.1021/ac701807v

Qin, J.-X., Yang, X.-G., Lv, C.-F., Li, Y.-Z., Liu, K.-K., Zang, J.-H., et al. (2021). Nanodiamonds: Synthesis, Properties, and Applications in Nanomedicine. Mater. Des. 210, 110091. doi:10.1016/j.matdes.2021.110091

Refsum, H., Ueland, P. M., Nygård, O., and Vollset, S. E. (1998). Homocysteine and Cardiovascular Disease. Annu. Rev. Med. 49, 31-62. doi:10.1146/ annurev.med.49.1.31

Richie, J. P., Skowronski, L., Abraham, P., and Leutzinger, Y. (1996). Blood Glutathione Concentrations in a Large-Scale Human Study. Clin. Chem. 42, 64-70.

Shenderova, O., Koscheev, A., Zaripov, N., Petrov, I., Skryabin, Y., Detkov, P., et al. (2011). Surface Chemistry and Properties of Ozone-Purified Detonation Nanodiamonds. J. Phys. Chem. C 115, 9827-9837. doi:10.1021/jp1102466

Shimkunas, R. A., Robinson, E., Lam, R., Lu, S., Xu, X., Zhang, X.-Q., et al. (2009). Nanodiamond-insulin Complexes as $\mathrm{pH}$-dependent Protein Delivery Vehicles. Biomaterials 30, 5720-5728. doi:10.1016/j.biomaterials.2009.07.004 
Song, Y., Wang, X., Zhao, C., Qu, K., Ren, J., and Qu, X. (2010). Label-free Colorimetric Detection of Single Nucleotide Polymorphism by Using SingleWalled Carbon Nanotube Intrinsic Peroxidase-like Activity. Chem. Eur. J. 16, 3617-3621. doi:10.1002/chem.200902643

Su, L.-J., Lin, H.-H., Wu, M.-S., Pan, L., Yadav, K., Hsu, H.-H., et al. (2019). Intracellular Delivery of Luciferase with Fluorescent Nanodiamonds for DualModality Imaging of Human Stem Cells. Bioconjug. Chem. 30, 2228-2237. doi:10.1021/acs.bioconjchem.9b00458

Sun, H., Zhao, A., Gao, N., Li, K., Ren, J., and Qu, X. (2015). Deciphering a Nanocarbon-Based Artificial Peroxidase: Chemical Identification of the Catalytically Active and Substrate-Binding Sites on Graphene Quantum Dots. Angew. Chem. Int. Ed. 54, 7176-7180. doi:10.1002/anie.201500626

Wang, H., Li, P., Yu, D., Zhang, Y., Wang, Z., Liu, C., et al. (2018a). Unraveling the Enzymatic Activity of Oxygenated Carbon Nanotubes and Their Application in the Treatment of Bacterial Infections. Nano Lett. 18, 3344-3351. doi:10.1021/ acs.nanolett.7b05095

Wang, Q., Chen, J., Zhang, H., Wu, W., Zhang, Z., and Dong, S. (2018b). Porous Co3O 4 Nanoplates with pH-Switchable Peroxidase- and Catalase-like Activity. Nanoscale 10, 19140-19146. doi:10.1039/c8nr06162a

Wang, Q., Zhang, L., Shang, C., Zhang, Z., and Dong, S. (2016). Triple-enzyme Mimetic Activity of Nickel-Palladium Hollow Nanoparticles and Their Application in Colorimetric Biosensing of Glucose. Chem. Commun. 52, 5410-5413. doi:10.1039/c6cc00194g

Wang, Q., Zhang, X., Huang, L., Zhang, Z., and Dong, S. (2017). One-Pot Synthesis of Fe3O4 Nanoparticle Loaded 3D Porous Graphene Nanocomposites with Enhanced Nanozyme Activity for Glucose Detection. ACS Appl. Mater. Inter. 9, 7465-7471. doi:10.1021/acsami.6b16034

Wehling, J., Dringen, R., Zare, R. N., Maas, M., and Rezwan, K. (2014). Bactericidal Activity of Partially Oxidized Nanodiamonds. Acs Nano 8, 6475-6483. doi:10.1021/nn502230m

Xia, X., Zhang, J., Lu, N., Kim, M. J., Ghale, K., Xu, Y., et al. (2015). Pd-Ir Core-Shell Nanocubes: A Type of Highly Efficient and Versatile Peroxidase Mimic. Acs Nano 9, 9994-10004. doi:10.1021/acsnano.5b03525

Xing, Y., and Dai, L. (2009). Nanodiamonds for Nanomedicine. Nanomedicine 4, 207-218. doi:10.2217/17435889.4.2.207

Xu, Y., Chen, X., Chai, R., Xing, C., Li, H., and Yin, X.-B. (2016). A Magnetic/ fluorometric Bimodal Sensor Based on a Carbon Dots-MnO2platform for Glutathione Detection. Nanoscale 8, 13414-13421. doi:10.1039/c6nr03129c
Yan, X., Song, Y., Zhu, C., Song, J., Du, D., Su, X., et al. (2016). Graphene Quantum Dot-MnO2 Nanosheet Based Optical Sensing Platform: A Sensitive Fluorescence "Turn Off-On" Nanosensor for Glutathione Detection and Intracellular Imaging. ACS Appl. Mater. Inter. 8, 21990-21996. doi:10.1021/ acsami.6b05465

Zhang, L., Han, L., Hu, P., Wang, L., and Dong, S. (2013). TiO2 Nanotube Arrays: Intrinsic Peroxidase Mimetics. Chem. Commun. 49, 10480-10482. doi:10.1039/ c3cc46163g

Zhang, S., Ong, C.-N., and Shen, H.-M. (2004). Critical Roles of Intracellular Thiols and Calcium in Parthenolide-Induced Apoptosis in Human Colorectal Cancer Cells. Cancer Lett. 208, 143-153. doi:10.1016/ j.canlet.2003.11.028

Zhang, X., Hu, W., Li, J., Tao, L., and Wei, Y. (2012). A Comparative Study of Cellular Uptake and Cytotoxicity of Multi-Walled Carbon Nanotubes, Graphene Oxide, and Nanodiamond. Toxicol. Res. 1, 62-68. doi:10.1039/ c2tx20006f

Zheng, J., Ma, L., Xin, B., Olah, T., Humphreys, W. G., and Zhu, M. (2007). Screening and Identification of GSH-Trapped Reactive Metabolites Using Hybrid Triple Quadruple Linear Ion Trap Mass Spectrometry. Chem. Res. Toxicol. 20, 757-766. doi:10.1021/tx600277y

Conflict of Interest: The authors declare that the research was conducted in the absence of any commercial or financial relationships that could be construed as a potential conflict of interest.

Publisher's Note: All claims expressed in this article are solely those of the authors and do not necessarily represent those of their affiliated organizations, or those of the publisher, the editors and the reviewers. Any product that may be evaluated in this article, or claim that may be made by its manufacturer, is not guaranteed or endorsed by the publisher.

Copyright (C) 2022 Liu, Yan, Huang, Sun, Zhang, Fu, Li and Jin. This is an openaccess article distributed under the terms of the Creative Commons Attribution License (CC BY). The use, distribution or reproduction in other forums is permitted, provided the original author(s) and the copyright owner(s) are credited and that the original publication in this journal is cited, in accordance with accepted academic practice. No use, distribution or reproduction is permitted which does not comply with these terms. 